\title{
Recurrent Laryngeal Carcinoma
}

National Cancer Institute

\section{Source}

National Cancer Institute. Recurrent Laryngeal Carcinoma. NCI Thesaurus. Code C4034.

The reemergence of laryngeal carcinoma after a period of remission. 